\title{
Comparative biometric study between plateau iris configuration and primary open angle glaucoma with narrow angle
}

\author{
Estudo biométrico comparativo entre configuração da íris em platô \\ e glaucoma primário de ângulo aberto com seio camerular estreito
}

\author{
Alberto Diniz Filho' \\ Sebastião Cronemberger ${ }^{2}$ \\ Rafael Vidal Mérula ${ }^{3}$ \\ Nassim Calixto ${ }^{4}$
}

From the Department of Ophthalmology and Otorrinolaringology - Federal University of Minas Gerais UFMG - Belo Horizonte - Brazil.

Postgraduate Student, School of Medicine, Universidade Federal de Minas Gerais - UFMG - Belo Horizonte (MG) - Brazil.

${ }^{2}$ Professor of Ophthalmology, School of Medicine of UFMG - Belo Horizonte (MG) - Brazil.

${ }^{3}$ Postgraduate Student, School of Medicine of UFMG Belo Horizonte (MG) - Brazil.

${ }^{4}$ Professor of Ophthalmology, School of Medicine of UFMG - Belo Horizonte (MG) - Brazil.

Address for correspondence: Alberto Diniz Filho. Avenida Afonso Pena, 270 - Curvelo (MG)

CEP 35790-000

E-mail: adinizfilho@yahoo.com.br

Recebido para publicação em 19.10.2008

Última versão recebida em 04.02.2009

Aprovação em 16.03.2009

\begin{tabular}{l} 
ABSTRACT \\
\hline Purpose: To investigate biometrically the differences between plateau \\
iris configuration (PIC) eyes and primary open angle glaucoma with \\
narrow angle eyes. Methods: A comparative study involving a case \\
series with 20 eyes of 11 plateau iris configuration patients and 45 eyes \\
of 27 primary open angle glaucoma with narrow angle eyes patients was \\
done. The following measurements were taken: corneal curvature, cen- \\
tral corneal thickness, anterior chamber depth, lens thickness $(\mathrm{LT})$, \\
axial length (AL), lens thickness and axial length ratio, lens position \\
(LP) and relative lens position (RLP). Results: The plateau iris con- \\
figuration eyes presented a higher corneal cuvature value than primary \\
open angle glaucoma with narrow angle eyes eyes but not with clinical \\
and statistical difference $(P=0.090)$. The plateau iris configuration \\
eyes demonstrated a higher central corneal thickness, with statistical \\
significance, when compared to primary open angle glaucoma with \\
narrow angle eyes $(P=0.010)$. Statistical significant difference between \\
plateau iris configuration and primary open angle glaucoma with \\
narrow angle eyes was found in axial length $(21.69 \pm 0.98$ vs. $22.42 \pm$ \\
$0.89 ; P=0.003)$. No significant difference was found when anterior \\
chamber depth $(2.62 \pm 0.23$ vs. $2.71 \pm 0.31 ; P=0.078), \mathrm{LT}(4.67 \pm 0.36 \mathrm{vs.}$ \\
$4.69 \pm 0.45 ; P=0.975), \mathrm{LT} / \mathrm{AL}(2.16 \pm 0.17$ vs. $2.10 \pm 0.21 ; P=0.569), \mathrm{LP}$ \\
(4.95 \pm 0.25 vs. $5.06 \pm 0.34 ; P=0.164)$ and RLP $(0.23 \pm 0.01$ vs. $0.22 \pm 0.14 ;$ \\
$P=0.348)$ were evaluated. Conclusion: The eyes with plateau iris \\
configuration presented statistical significantly shorter axial length \\
and higher central corneal thickness than primary open angle glaucoma \\
with narrow angle eyes.
\end{tabular}

Keywords: Glaucoma, angle-closure; Anterior chamber/ultrasonography; Gonioscopy; Iris diseases; Intraocular pressure; Comparative study

\section{INTRODUCTION}

In general, anterior chamber depth $(\mathrm{ACD})$ is well correlated with angle width. However, in a few cases, the occurrence of narrow angle (NA) in eyes with anterior chamber of relatively normal depth and a relatively flat iris was noted as early as $1940^{(1)}$.

Törnquist was the first to use the term plateau type of iris describing an acute case of glaucoma in a 44-year-old man with angle-closure glaucoma that had a normal anterior chamber depth, flat iris surface, which in its most peripheral part curved sharply backwards to produce a rather $\mathrm{NA}^{(2)}$. 
Plateau iris configuration (PIC) was defined as presurgical changes of an eye with a relative normal central ACD, flat iris by conventional biomicroscopy, but displaying an extremely narrow or closed angle on gonioscopic examination. On the other hand, plateau iris syndrome (PIS) was defined as an acute glaucoma crisis in one eye with a relative normal central ACD and patent iridotomy on direct examination, presenting angle closure confirmed by gonioscopic examination after mydriasis ${ }^{(2-5)}$.

Plateau iris has been considered an anatomic variant of iris structure in which the iris periphery angulates sharply forward from its insertion point and then again angulates sharply and centrally backward. Iris surface appears relatively flat, giving the iris the appearance of a plateau in sagittal section ${ }^{(6)}$. Complete and incomplete plateau iris are defined by the level of the iris relative to Schwalbe's line and the structures of the angle. The angle of PIC eyes has additional characteristics, besides the isolated morphologic features of eyes with NA.

The aim of this paper was to investigate biometrically the differences between PIC and primary open angle glaucoma with narrow angle (POAGNA) eyes, when only the anterior part of trabecular meshwork was identifiable by conventional gonioscopy and the angle was open with indentation gonioscopy.

\section{METHODS}

This prospective observational case-control study evaluated 38 consecutive patients. Plateau iris configuration and POAGNA subjects were recruited from the Glaucoma Service of São Geraldo Hospital of Federal University of Minas Gerais from September 2005 to October 2007. The study was carried out after approval from the Federal University of Minas Gerais Research Ethics Committee through Certificate 226/05.

The following criteria were used to define cases of PIC: 1 ) peripheral iris anteriorly and centrally angled; 2) a slightly convex iris by conventional biomicroscopy; 3 ) narrow open angle evaluated by gonioscopy (posterior portion of trabecular meshwork hidden) based upon the most posterior structure visible in the angle; 4) sign of double hump with indentation gonioscopy; and 5) presence of an anteriorly directed ciliary body, an absent ciliary sulcus, a steep iris from its point of insertion followed by a downward angulation and an iridoangle contact (above the level of scleral spur) on ultrasound biomicroscopy (UBM) examination performed on the four quadrants (superior, inferior, nasal and temporal).

The criteria used to define POAGNA were: 1) intraocular pressure (IOP) higher than $18 \mathrm{mmHg}$; 2) presence of glaucomatous optic neuropathy defined by at least two of the following items: cup/disc ratio ( $/ \mathrm{D} / \mathrm{D})$ asymmetry between fellow eyes greater than 0.2 , rim thinning, notching, cup/disc ratio (C/ D ) more than 0.7, optic disc haemorrhage or retinal nerve fiber layer (RNFL) defect; 3) glaucomatous visual field defects were detected by automated perimetry evaluated by means of
Interzeag Octopus 1-2-3 (visual field test was considered abnormal if two of the following three criteria were met on at least two consecutive visual fields: (a) an abnormal Bebie curve (deviation more than 0.5); (b) 3 contiguous nonedge points (allowing the two nasal step edge points) on a Octopus program G1X visual field with $P<0.05$ on the probability plot, with at least 1 point at $P<0.01$; and (c) a corrected loss variance $P<0.05$; and 4) narrow open angle evaluated by gonioscopy (the posterior portion of trabecular meshwork was hidden) based upon the most posterior structure visible in the angle.

Exclusion criteria used were the following: nuclear sclerosis defined as Lens Opacities Classification System (LOCS) II more than grade 2 (NC2, NO2) $)^{(7)}$; secondary glaucoma; acute primary angle-closure (APAC), defined by the following criteria: 1) presence of at least two of the following symptoms: ocular or periocular pain, nausea and/or vomiting, antecedent history of intermittent blurring of vision with haloes; and 2) presenting intraocular pressure (IOP) higher than $28 \mathrm{mmHg}$ (as measured by Goldmann applanation tonometry) and presence of at least three of the following signs: conjunctival injection, corneal epithelial edema, mid-dilated unreactive pupil, and shallow anterior chamber; and 3) presence of an occluded angle in the affected eye, verified by gonioscopy; requirement of surgical management, such as laser peripheral iridotomy (LPI) or trabeculectomy; signs of previous glaucoma acute attack, such as sectorial iris atrophy, "glaukomflecken", or peripheral anterior synechia; corneal opacity in both eyes; previous surgical procedure; and closed angle under dark gonioscopic examination.

Clinical examination consisted of history, visual acuity with and without optical correction, slit-lamp biomicroscopy, gonioscopy and $\mathrm{C} / \mathrm{D}$ examination by indirect ophthalmoscopy. Gonioscopy was done by one of the authors (ADF) and confirmed by another investigator (SC), using a Goldmann threemirror goniolens (Haag-Streit AG, Köniz, Switzerland), and after, a Zeiss four-mirror goniolens (Carl Zeiss Meditec AG, Oberkochen, Germany) to perform indentation gonioscopy, in undilated state under room light illumination (approximately 240 lux), and dark (approximately 0.1 lux) room was darkened in 5 minutes, both conditions previously measured with an illumination meter (Minolta T10 Illumination Meter, Konica Minolta Sensing Inc., Osaka, Japan), being uniforms the conditions for all examination. Gonioscopy classification currently used by the Glaucoma Service, both in primary gaze and under indentation, was adopted in this study and applied in room light illumination: 1) wide open angle (angle totally open); 2) intermediate open angle (when it was possible to see until scleral spur, but the ciliary band was not identifiable); 3) narrow open angle (when only the anterior part of trabecular meshwork was identifiable); 4) closed angle (no identifiable structure). The angle was gonioscopically evaluated in the superior and inferior quadrants $\left(180^{\circ}\right)$.

Biometric parameters were captured by A-mode contact ultrasonography (DGH 5100e; DGH Technologies, Exton, USA) and consisted of anterior chamber depth (ACD), lens thickness 
(LT) and axial length (AL). Additionally, central corneal thickness (CCT) and corneal curvature $(\mathrm{K})$, using the average keratometry value from vertical and horizontal meridians were respectively evaluated by an ultrasonic pachymeter (DGH 5100e; DGH Technologies, Exton, USA) and Bausch \& Lomb keratometer (Bausch \& Lomb Optical Co., Rochester, USA).

Ratio between LT and AL was defined as LT/AL, lens position (LP) was defined as ACD + 1/2 LT and relative lens position (RLP) was defined as LP/AL.

Statistical analyses were performed using Statistical Package for Social Sciences for Windows version 16.0.1 (SPSS, Inc., Cary, NC, USA).

Frequency histograms and one-sample Kolmogorov-Smirnov test were used to assess the distribution of numeric data for parametric characteristics. Difference in mean values of parametric data among eyes of different patients was examined using independent samples Student's $t$ test. For nonparametric data, a Mann-Whitney $U$ test was used to compare means of independent samples. Pearson's chi-square test for independence was used to evaluate differences among proportions. A $P$ value of less than 0.05 was considered statistically significant.

\section{RESULTS}

Demographic features of the 38 patients included in the study are shown in Table 1. No statistical difference was found between the two groups when age $(P=0.382)$, gender $(P=0.520)$, race $(P=0.515)$ and familiar history of glaucoma $(P=0.241)$ were compared.

Twenty eyes of 11 PIC patients and 45 eyes of 27 POAGNA patients were evaluated. Table 2 shows the clinical characteristics: uncorrected visual acuity (UCVA), best corrected visual acuity (BCVA), spherical equivalent (SE), intraocular pressure (IOP), gonioscopy, K and CCT of PIC and POAGNA eyes, and the statistical significance of the differences between the groups. Significant differences were found between PIC and POAGNA eyes in relation to UCVA $(P=0.018)$, BCVA $(P=0.001)$, and $\mathrm{C}_{\mathrm{D}}$ ratio $(P=0.046)$. On the contrary, there was no significant difference between PIC and POAGNA eyes when SE $(P=0.787)$ and IOP $(P=0.316)$ were evaluated.

In primary gaze, all PIC and POAGNA eyes showed narrow open angle. By indentation gonioscopy, 75.6\% (n=34) of POAGNA eyes were classified as wide open angle. Again, no statistically significant differences were evident when POAGNA eyes were compared to PIC eyes $(P=0.179)$ (Table 2$)$ under indentation.

Plateau iris configuration eyes had marginally a higher $\mathrm{K}$ value than POAGNA eyes with no statistical difference $(P=0.090)$. Narrow angle eyes demonstrated a thinner CCT, with statistical significance, when compared to PIC $(P=0.010)$.

Table 3 shows ocular biometric parameters in PIC and POAGNA eyes, and statistical significant differences between these groups. Statistical significant difference between PIC and POAGNA eyes was found only in the AL (21.69 \pm 0.98 vs.
22.42 $\pm 0.89 ; P=0.003)$. No significant difference between PIC and POAGNA eyes was demonstrated when ACD (2.62 \pm 0.23 vs. $2.71 \pm 0.31 ; P=0.078), \mathrm{LT}(4.67 \pm 0.36$ vs. $4.69 \pm 0.45$; $P=0.975), \mathrm{LT} / \mathrm{AL}(2.16 \pm 0.17$ vs. $2.10 \pm 0.21 ; P=0.569), \mathrm{LP}$ $(4.95 \pm 0.25$ vs. $5.06 \pm 0.34 ; P=0.164)$ and $\operatorname{RLP}(0.23 \pm 0.01$ vs. $0.22 \pm 0.14 ; P=0.348)$ were compared.

\section{DISCUSSION}

Both groups had similar demographic characteristics (Table 1). Plateau iris configuration patients had a mean age of $59.8 \pm 11.3$ years which was lower than the mean age of the POAGNA patients $(65.9 \pm 9.0$ years $)$. However, no statistical difference was found between the two groups when age $(P=0.382)$, gender $(P=0.520)$, race $(P=0.515)$ and familiar history of glaucoma $(P=0.241)$ were compared.

It was reported in one study that patients with PIC who develop angle-closure glaucoma are generally younger than those with primary angle-closure glaucoma ${ }^{(3)}$. This study showed that patients with PIS had a mean age of 39.6 years on first presentation (range, 22-49 years) ${ }^{(3)}$.

In a retrospective study that evaluated the angle closure etiology in young patients, PIS was responsible for the highest frequency of closure revealed in 35 (52.2\%) out of the 67 patients with angle closure glaucoma. Patients with PIS were mostly women $(74.3 \%)$, young (34.9 years old on average), less hypermetropic than the patients with pupillary block who, very often, have a family history of angle-closure glaucoma ${ }^{(8)}$.

Some studies emphasize that the etiology of angle-closure in relatively young patients differs from that of an older population, with a clear female prevalence in both $^{(8-10)}$. No age and gender predisposition have been observed in the present paper.

The POAGNA eyes demonstrated better UCVA and BCVA than the PIC eyes (Table2). In agreement with other stu$\operatorname{dies}^{(11)}$, the hypermetropic spherical equivalent was the most common refraction finding in both groups.

The POAGNA eyes presented higher $\mathrm{C} / \mathrm{D}$ ratio with statistically significant difference (Table 2). This is probably related to the fact that POAG is a chronic disease with no symptoms and, many times, a later diagnosis.

Some studies have shown that eyes that had acute primary angle-closure, compared to normal eyes, have shorter AL, shallower anterior chamber, smaller radius of anterior corneal curvature, smaller radius of posterior corneal curvature, smaller radius of anterior lens curvature, thicker lens, more anterior lens position (LP), and higher lens thickness (LT) to ocular AL ratio $^{(12-14)}$. Other studies have compared POAG and APAC glaucoma eyes $^{(15)}$ and APAC glaucoma and contralateral eyes ${ }^{(16)}$.

In this study, PIC eyes had thicker corneas compared to POAGNA eyes. It seems to be the first study in which CCT was compared between PIC and POAGNA eyes.

The biometric features in our series of patients with PIC were similar to other reports ${ }^{(16-18)}$. In the present study, a sta- 


\begin{tabular}{|c|c|c|c|}
\hline & PIC $n=11$ & POAGNA $n=27$ & $P$ value \\
\hline Age (years) & $59.8 \pm 11.3$ & $65.9 \pm 9.0$ & $0.382^{a}$ \\
\hline Gender & & & $0.520^{b}$ \\
\hline$\%$ male & $36.4(4)$ & $25.9(7)$ & \\
\hline$\%$ female & $63.6(7)$ & $74.1(20)$ & \\
\hline Race & & & $0.515^{b}$ \\
\hline$\%$ leukodermic & $54.5(6)$ & $48.1(13)$ & \\
\hline$\%$ feodermic & $45.5(5)$ & $40.8(11)$ & \\
\hline$\%$ melanodermic & $0.0(0)$ & $11.1(3)$ & \\
\hline Familiar history of glaucoma & & & $0.241^{b}$ \\
\hline$\%$ positive & $36.4(4)$ & $18.5(5)$ & \\
\hline$\%$ negative & $63.6(7)$ & $81.5(22)$ & \\
\hline
\end{tabular}

\begin{tabular}{|c|c|c|c|}
\hline & $P I C n=20$ & POAGNA $n=45$ & $\boldsymbol{P}$ value \\
\hline Uncorrected visual acuity (LogMAR) & $0.48 \pm 0.71$ & $0.41 \pm 0.30$ & $0.018^{\mathrm{a}}$ \\
\hline Best corrected visual acuity (LogMAR) & $0.31 \pm 0.72$ & $0.12 \pm 0.23$ & $0.001^{\mathrm{a}}$ \\
\hline Spherical equivalent (dioptres) & $+1.29 \pm 2.28$ & $+1.28 \pm 2.03$ & $0.787^{a}$ \\
\hline IOP $(\mathrm{mmHg})$ & $13.65 \pm 4.18$ & $15.84 \pm 4.66$ & $0.316^{\mathrm{a}}$ \\
\hline$C / D$ & $0.44 \pm 0.15$ & $0.58 \pm 0.20$ & $0.046^{a}$ \\
\hline \multicolumn{4}{|l|}{ Gonioscopy } \\
\hline Primary position of gaze & & & $-\mathrm{b}$ \\
\hline$\%$ intermediary open angle $(n)$ & $0.0(0)$ & $0.0(0)$ & \\
\hline$\%$ narrow open angle $(n)$ & $100.0(20)$ & $100.0(45)$ & \\
\hline$\%$ closed angle ${ }^{\star}(n)$ & $0.0(0)$ & $0.0(0)$ & \\
\hline Under indentation & & & $0.179^{c}$ \\
\hline$\%$ wide open angle ${ }^{\star}(n)$ & $90.0(18)$ & $75.6(34)$ & \\
\hline$\%$ intermediary open angle $(n)$ & $10.0(2)$ & $24.4(11)$ & \\
\hline$\%$ narrow open angle* $(n)$ & $0.0(0)$ & $0.0(0)$ & \\
\hline$\%$ closed angle* $(n)$ & $0.0(0)$ & $0.0(0)$ & \\
\hline K (dioptres) & $44.71 \pm 1.08$ & $44.16 \pm 1.62$ & $0.090^{d}$ \\
\hline CCT $(\mu \mathrm{m})$ & $540.30 \pm 32.06$ & $518.84 \pm 27.77$ & $0.010^{d}$ \\
\hline
\end{tabular}

\begin{tabular}{|c|c|c|c|}
\hline & PIC $n=20$ & POAGNA $n=45$ & $P$ value \\
\hline Anterior chamber depth (mm) & $2.62 \pm 0.23$ & $2.71 \pm 0.31$ & $0.078^{a}$ \\
\hline Lens thickness (mm) & $4.67 \pm 0.36$ & $4.69 \pm 0.45$ & $0.975^{a}$ \\
\hline Axial length (mm) & $21.69 \pm 0.98$ & $22.42 \pm 0.89$ & $0.003^{b}$ \\
\hline Lens thickness/axial length ratio (LT/AL) & $2.16 \pm 0.17$ & $2.10 \pm 0.21$ & $0.569^{a}$ \\
\hline Lens position (mm) & $4.95 \pm 0.25$ & $5.06 \pm 0.34$ & $0.164^{\mathrm{a}}$ \\
\hline Relative lens position & $0.23 \pm 0.01$ & $0.22 \pm 0.14$ & $0.348^{b}$ \\
\hline
\end{tabular}

tistical significant difference between PIC and POAGNA of glaucomatous eyes was evident in $\operatorname{AL}(P=0.003)$ (Table 3$)$ and $\operatorname{CCT}(P=0.010)$ (Table 2).

No significant differences between PIC and POAGNA of glaucomatous eyes were found when ACD, LT, LT/AL, LP and RLP were evaluated, although, eyes with PIC had shallower anterior chamber, shorter AL, more anterior LP and higher values of LT/AL than POAGNA eyes (Table 3). Taking these findings into consideration, it is advisable to take care when the pupil dilation is required in PIC eyes.

These characteristics have already been found in other studies that compared anterior chamber dimensions in patients with clinical diagnosis of POAGNA and acute, fellow eye of acute, subacute, or chronic angle-closure glaucoma ${ }^{(16-17)}$. In one 
of those, the mean ACD of 16 PIC eyes studied was $2.19 \mathrm{~mm} \pm$ $0.26 \mathrm{~mm}^{(17)}$. We found a comparatively deeper anterior chamber $(2.62 \pm 0.23 \mathrm{~mm}$ in PIC eyes and $2.71 \pm 0.31 \mathrm{~mm}$ in POAGNA eyes). Although PIC patients were younger than POAGNA patients, no statistical difference was found in LT. However, shorter AL and higher values of LT/AL in PIC eyes compared to POAGNA eyes could explain the shallower ACD in PIC eyes.

Another study found that angle-closure glaucoma (ACG) eyes showed thicker LT, more anterior lens, and shallower anterior chamber when compared to other subgroups of glaucoma: chronic angle-closure glaucoma and subacute angleclosure glaucoma ${ }^{(18)}$. All ACG subgroups had no statistically significant difference in $\mathrm{AL}^{(18)}$.

A review of measurements of ACD in 318 eyes of 318 patients who had been diagnosed by UBM as having either pupillary block or PIS was performed ${ }^{(19)}$. Patients with PIS were previously submitted to an iridotomy. ACD was measured axially from the internal corneal surface to the anterior lens surface using ultrasound instrument's internal measuring capability. Review of the literature suggests that patients with PIS have a normal or deeper axial ACD compared to those with pupillary block. However, it was found that ACD associated with PIS is shallower than normal and also shallower than in pupillary block ${ }^{(19)}$. The authors did not mention the lens and the refractive status of patients ${ }^{(20)}$. All patients with pupillary block in that study had undergone a LPI, whereas those labelled as having PIS had a patent LPI ${ }^{(20)}$. Pupillary block and PIC are the most common mechanisms of primary angle closure, and they can coexist ${ }^{(20)}$.

Changes in ocular dimensions with aging, especially in the anterior segment, have already been studied ${ }^{(21-22)}$. It is assumed that the lens of these eyes is proportionally thicker than that of normal eyes, or of younger patients. If this is true, thicker lens associated to anatomic abnormality of the ciliary body's positioning can play a very important role in acute crisis of glaucoma caused by pupillary dilation. This hypothesis is supported by the fact that on eyes with PIC and cataract, from which cataract has been removed, the abnormal positioning of ciliary body persists, but an increase of ACD takes place, as well as widening of the angle, which prevents the installation of an acute crisis of glaucoma ${ }^{(23)}$.

\section{CONCLUSIONS}

This study showed that PIC eyes have significantly shorter AL than POAGNA eyes. The opposite occurs with CCT which is significantly higher in PIC eyes than in POAGNA eyes.

\section{RESUMO}

Objetivo: Comparar, biometricamente, olhos portadores de configuração da íris em platô (CIP) e olhos portadores de glaucoma primário de ângulo aberto com seio camerular estreito.
Métodos: Estudo prospectivo comparativo envolvendo 20 olhos de 11 pacientes portadores de íris em platô e 45 olhos de 27 pacientes portadores de glaucoma primário de ângulo aberto com seio camerular estreito. Os parâmetros avaliados foram: curvatura corneana, espessura central da córnea, profundidade central da câmara anterior, espessura do cristalino (EC), comprimento axial (CAx), relação entre a espessura do cristalino e o comprimento axial (EC/CAx), posição do cristalino (PC) e posição relativa do cristalino (PRC). Resultados: Os olhos com íris em platô apresentaram valores ceratométricos superiores àqueles dos olhos com glaucoma primário de ângulo aberto com seio camerular estreito, embora sem diferença clínica ou estatística $(P=0,090)$. Os olhos com configuração da íris em platô apresentaram maior espessura central da córnea com diferença estatisticamente significativa, quando comparados aos olhos com CIP $(P=0,010)$. Diferença estatisticamente significativa foi encontrada entre os olhos com configuração da íris em platô e os olhos com glaucoma primário de ângulo aberto com seio camerular estreito no CAx $(21,69 \pm 0,98$ vs. $22,42 \pm 0,89 ; P=0,003)$. Não houve diferença significativa entre: profundidade central da câmara anterior $(2,62 \pm 0,23$ e $2,71 \pm 0,31 ; P=0,078) ; \mathrm{EC}(4,67 \pm 0,36$ e $4,69 \pm 0,45 ; P=0,975) ;$ EC/CAx $(2,16 \pm 0,17$ e $2,10 \pm 0,21 ; P=0,569) ; \mathrm{PC}(4,95 \pm 0,25 \mathrm{e}$ $5,06 \pm 0,34 ; P=0,164)$ e PRC $(0,23 \pm 0,01$ e $0,22 \pm 0,14 ; P=0,348)$.

Conclusão: Os olhos com configuração da íris em platô possuem menor comprimento axial e maior espessura central da córnea em comparação aos olhos com glaucoma primário de ângulo aberto com seio camerular estreito, com significância estatística.

Descritores: Glaucoma de ângulo fechado; Câmara anterior/ ultrassonografia; Gonioscopia; Doenças da íris; Pressão intraocular; Estudo comparativo

\section{REFERENCES}

1. Gradle HS, Sugar HS. Concerning the chamber angle. III. A clinical method of goniometry. Am J Ophthalmol. 1940;23(8):1135-9.

2. Törnquist R. Angle-closure glaucoma in an eye with a plateau type of iris. Acta Ophthalmol. 1958;36(3):419-23.

3. Wand M, Grant WM, Simmons RJ, Hutchinson BT. Plateau iris syndrome. Trans Sect Ophthalmol Am Acad Ophthalmol Otolaryngol. 1977;83(1):122-30.

4. Lowe RF. Plateau iris. Aust J Ophthalmol. 1981;9(1):71-3.

5. Shaffer RN. Primary glaucomas. Gonioscopy, ophthalmoscopy and perimetry. Trans Am Acad Ophthalmol Otolaryngol. 1960;64(2):112-27.

6. Ritch R. Plateau iris is caused by abnormally positioned ciliary processes. J Glaucoma. 1992;1(1):23-6.

7. Chylack LT Jr, Leske MC, McCarthy D, Khu P, Kashiwagi T, Sperduto R. Lens Opacities Classification System II (LOCS II). Arch Ophthalmol 1989; 107(7):991-7. Comment in: Arch Ophthalmol. 1990;108(9):1209-10.

8. Ritch R, Chang BM, Liebmann JM. Angle-closure in younger patients. Ophthalmology. 2003;110(10):1880-9.

9. Stieger R, Kniestedt C, Sutter F, Bachmann LM, Stuermer J. Prevalence of plateau iris syndrome in young patients with recurrent angle-closure. Clin Experiment Ophthalmol. 2007;35(5):409-13. Comment in: Clin Experiment Ophthalmol. 2007;35(5):399-400.

10. Ritch R, Dorairaj S. Plateau iris syndrome in younger patients. Clin Experiment Ophthalmol. 2007;35(5):399-400. Comment in: Clin Experiment Ophthalmol. 2007;35(5):409-13.

11. Lowe RF. Causes of shallow anterior chamber in primary angle-closure glaucoma. 
Ultrasonic biometry of normal and angle-closure glaucoma eyes. Am J Ophthalmol. 1969;67(1):87-93.

12. Markowitz SN, Morin JD. The ratio of lens thickness to axial length for biometric standardization in angle-closure glaucoma. Am J Ophthalmol. 1985; 99(4):400-2.

13. Panek WC, Christensen RE, Lee DA, Fazio DT, Fox LE, Scott TV. Biometric variables in patients with occludable anterior chamber angles. Am J Ophthalmol. 1990;110(2):185-88.

14. Lowe RF. Aetiology of the anatomical basis for primary angle-closure glaucoma. Biometrical comparisons between normal eyes and eyes with primary angle-closure glaucoma. Br J Ophthalmol. 1970;54(3):161-9.

15. Calixto N, Cronemberger, S. Glaucoma simples x glaucoma agudo: estudo ecobiométrico. Arq Bras Oftalmol. 1986;49(1):1-8.

16. Mérula RV, Cronemberger S, Diniz Filho A, Calixto N. Análise morfométrica comparativa entre olhos com glaucoma agudo primário e olhos contralaterais. Arq Bras Oftalmol. 2008;71(3):321-7.

17. Lee DA, Brubaker RF, Ilstrup DM. Anterior chamber dimensions in patients with narrow angles and angle-closure glaucoma. Arch Ophthalmol. 1984;102(1):46-50.
18. Sihota R, Lakshmaiah NC, Agarwal HC, Pandey RM, Titiyal JS. Ocular parameters in the subgroups of angle closure glaucoma. Clin Experiment Ophthalmol. 2000;28(4):253-8.

19. Mandell MA, Pavlin CJ, Weisbrod DJ, Simpson ER. Anterior chamber depth in plateau iris syndrome and pupillary block as measured by ultrasound biomicroscopy. Am J Ophthalmol. 2003;136(5):900-3.

20. Li PS, Lai JS, Lam DS. Anterior chamber depth in plateau iris syndrome and pupillary block as measured by ultrasound biomicroscopy. Am J Ophthalmol. 2004;137(6):1169; author reply 1169-70. Comment in: Am J Ophthalmol. 2003;136(5):900-3; Am J Ophthalmol. 2004;137(1):38-42.

21. Markowitz SN, Morin JD. Angle-closure glaucoma: relation between lens thickness, anterior chamber depth and age. Can J Ophthalmol. 1984;19(7):300-2.

22. Souza Filho EC. Estudo da morfometria do segmento anterior em olhos normais pela biomicroscopia ultra-sônica [tese]. Belo Horizonte: Universidade Federal de Minas Gerais; 2002.

23. Tran HV, Liebmann JM, Ritch R. Iridociliary apposition in plateau iris syndrome persists after cataract extraction. Am J Ophthalmol. 2003;135(1):40-3. Comment in: Am J Ophthalmol. 2003;136(2):395; author reply 395-6.

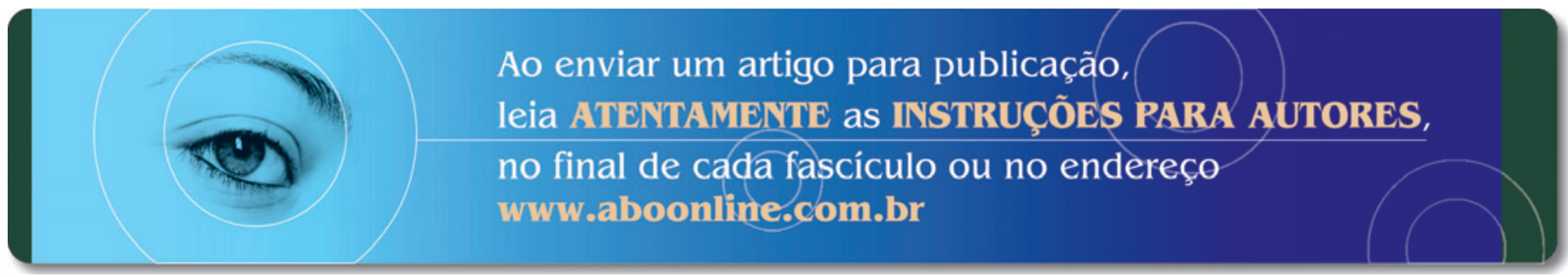

